\title{
Insulin glulisine in the management of diabetes
}

This article was published in the following Dove Press journal:

Diabetes, Metabolic Syndrome and Obesity:Targets and Therapy

2 July 2009

Number of times this article has been viewed

\section{Satoru Yamada ${ }^{1,2}$ \\ 'Diabetes Center, Kitasato Institute Hospital, Tokyo, Japan; ${ }^{2}$ Department of Internal Medicine, Keio University School of Medicine, Tokyo, Japan}

Abstract: Insulin glulisine is appealing in principle, but the advantages of this drug over the other rapid-acting insulin analogs are still relatively unknown. The frequency of hypoglycemia, convenience in the timing of administration, and improvements in terms of $\mathrm{HbA}_{1 \mathrm{c}}$ seem similar among the rapid-acting insulin analogs, including insulin glulisine. Only properly randomized longterm clinical studies with insulin glulisine will reveal the true value of this novel insulin analog.

Keywords: insulin analog, rapid-acting insulin, trometamol, polysorbate 20

\section{Background}

The discover of insulin in 1921 introduced a new era for the treatment of diabetes. After the DCCT study was reported in $1993^{1}$ and the UKPDS was reported in 1998, 2,3 it was assumed that tight glycemic control is important to prevent diabetic complications in both type 1 and type 2 diabetes. Because the ACCORD study ${ }^{4}$ showed the difficulties in achieving tight glycemic control without harmful hypoglycemic episodes and the ADVANCE $^{5}$ and $\mathrm{VADT}^{6}$ studies revealed the difficulties in preventing cardiovascular complications, patients with diabetes need more effective and safer treatment strategies.

Type 2 diabetes is a progressive disease characterized by relentless deterioration of pancreatic beta cell function, ${ }^{7}$ and the incidence of type 2 diabetes is increasing, particularly in younger individuals. ${ }^{8}$ These facts suggest that an increasing number of patients with type 2 diabetes will ultimately require insulin therapy. Therefore, insulin analogs have been developed to mimic physiological insulin action, which allow tighter glycemic control with reduced risk of severe hypoglycemic episodes and offer good quality of life (QOL) in the absence of complications.

\section{Development of insulin analogs}

Figure 1a shows the molecular structure of insulin, which has a molecular weight of about $6000 \mathrm{kDa}$ and consists of an A chain with 21 amino acids and a B chain with 30 amino acids. ${ }^{9}$

The N-terminal of the A chain and the $\mathrm{C}$-terminal of the $\mathrm{B}$ chain are the sites that bind to the insulin receptor. Thus, substitution in these amino acids will alter the avidity to the insulin receptor and the activity of the analog as an insulin receptor agonist. In addition, insulin forms stabile hexamers centered on $\mathrm{Zn}$ in solution. When this hexamer is injected subcutaneously, at first it will be resolved to a dimer and then a monomer, which is the absorbable form. The C-terminal of the B chain is critical in the formation of the dimer. Thus, substitution of amino acids in this area affects the conversion from the hexamer to
Diabetes Center, Kitasato Institute Hospital, 5-9-I Shirokane, Minato-ku, Tokyo 108-8642, Japan

$\mathrm{Tel}+8|33444-6| 6 \mid$

Fax +8I 3 448-0553

Email yamada-s@insti.kitasato-u.ac.jp 
the monomer and may aid rapid absorption. So far, three kinds of rapid-acting insulin analog have been introduced, namely insulin lispro, insulin aspart and insulin glulisine.

In insulin lispro, the natural sequence of proline at position B28 and lysine at position B29 is reversed (Figure 1b). ${ }^{10}$ In insulin aspart, the natural sequence of proline at position B28 is substituted by aspartic acid (Figure 1c). ${ }^{11}$ As these changes suggest, position B28 is a locus involved in dimer formation.

\section{Structure of insulin glulisine}

In insulin glulisine, the natural sequence of asparagine at position B3 and lysine at position B29 are substituted by lysine and glutamic acid, respectively (Figure 1d). ${ }^{12,13}$ This structure of insulin glulisine affects not only self-association but also the isoelectric point, which is shifted lower ( $\mathrm{pH} 5.1$; human insulin, $\mathrm{pH}$ 5.5), which enhances its solubility at a physiologic $\mathrm{pH}$. As a consequence, unlike other insulin analogs that lack proline at B28, insulin glulisine is more likely to self-associate into dimers in the absence of ligands. Thus, there are several important differences between insulin glulisine and the other rapid-acting insulin analogs, insulin lispro and insulin aspart (Table 1). The insulin glulisine solution does not contain hexamer-promoting $\mathrm{Zn}$, but does include polysorbate 20 as a stabilizer and trometamol as a buffer. Polysorbate 20 is also known commercially as Tween 20. This is used as an excipient in pharmaceutical applications to stabilize emulsions and suspensions. Purified protein derivative (PPD) solution, which contains polysorbate 20, is used in skin testing for tuberculosis exposure. Trometamol is known as Tris or THAM and is extensively used in biochemistry and molecular biology. In a clinical setting, trometamol is used as an alternative to sodium bicarbonate

\section{A}

A chain
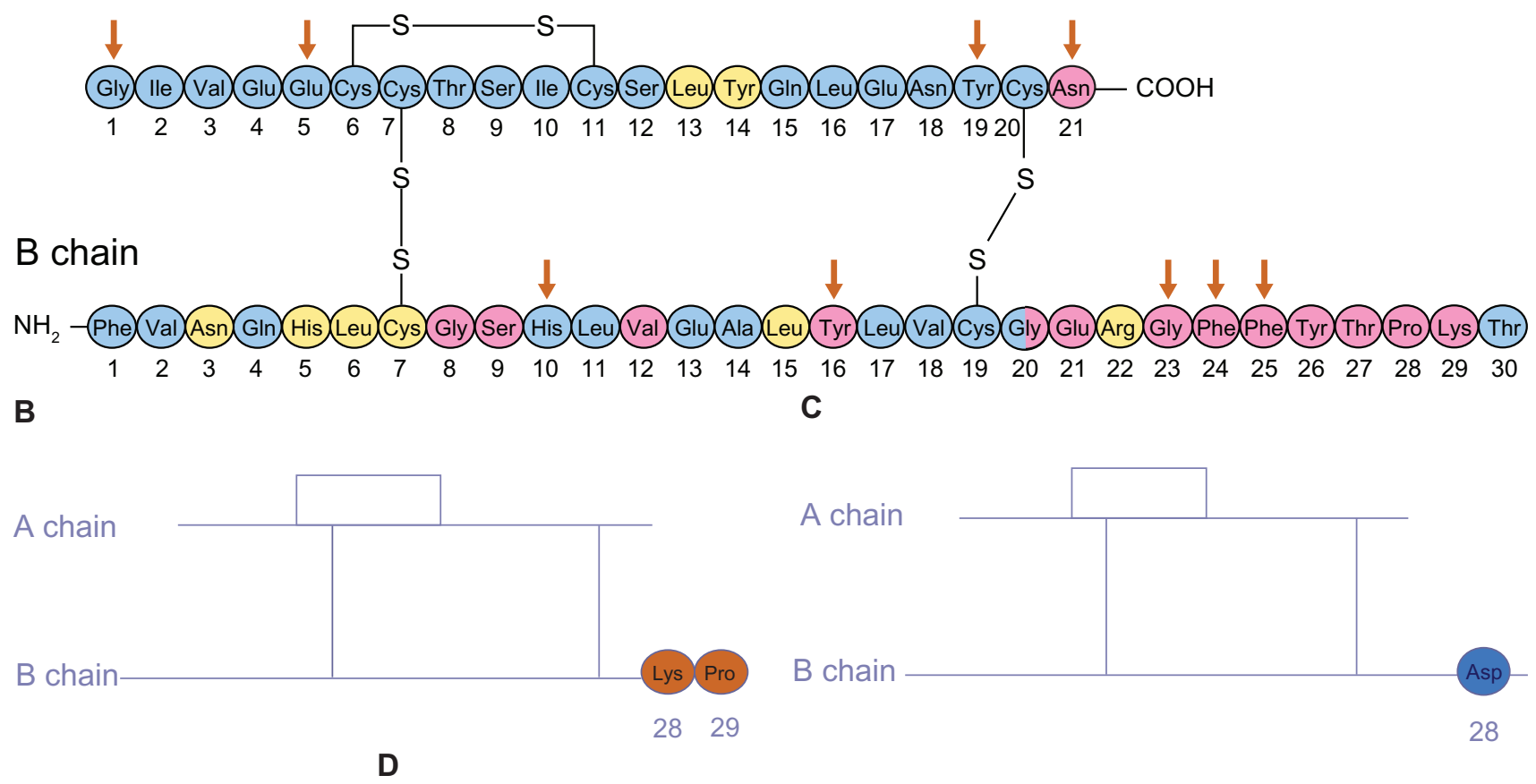

D

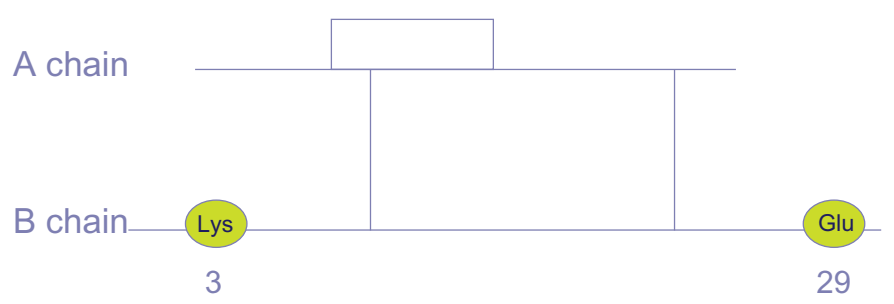

Figure I The amino acid sequence of human insulin and rapid-acting insulin analogs. Pink circles: amino acid residues involved in dimer formation. Blue circles: amino acid residues involved in hexamer formation. Arrow: amino acid residues involved in binding with the insulin receptor. A) human insulin, B) insulin lispro, C) insulin aspart, and D) insulin glulisine. 
Table I Comparison of regular human insulin and rapid-acting insulin analogs

\begin{tabular}{|c|c|c|c|c|c|c|}
\hline & & & Human insulin & Insulin lispro & Insulin aspart & Insulin glulisine \\
\hline \multirow[t]{7}{*}{ Insulin action } & Onset & $\min$ & $30-60$ & $5-15$ & $5-15$ & $5-15$ \\
\hline & Peak & $\mathrm{h}$ & $2-3$ & $0.5-1.5$ & $0.5-1.5$ & $0.5-1.5$ \\
\hline & \multirow[t]{4}{*}{$\mathrm{C}_{\max }$} & $\mu g / L$ & $0.6-2.5$ & $0.8-4.1$ & & \\
\hline & & $\mathrm{pmol} / \mathrm{L}$ & $195-260$ & & $34 I-506$ & \\
\hline & & $\mathrm{mU} / \mathrm{L}$ & $40 \pm 10$ & & & $73 \pm 16$ \\
\hline & & ratio & 100 & 222 & 175 & 183 \\
\hline & Duration & $\mathrm{hr}$ & $6-10$ & $4-5$ & $4-5$ & $4-5$ \\
\hline \multirow[t]{3}{*}{ Excipients } & \multicolumn{2}{|l|}{ Zinc } & + & + & + & - \\
\hline & \multicolumn{2}{|c|}{ Polysorbate 20} & - & - & - & + \\
\hline & \multicolumn{2}{|c|}{ Trometamol } & - & - & - & + \\
\hline \multirow{5}{*}{$\begin{array}{l}\text { Receptor binding and } \\
\text { mitogenic potencies }\end{array}$} & \multicolumn{2}{|c|}{ Insulin receptor affinity (\%) } & 100 & $84 \pm 6$ & $92 \pm 6$ & $68-7 \mid$ \\
\hline & \multicolumn{2}{|c|}{ Insulin receptor off-rate (\%) } & 100 & $100 \pm 11$ & $81 \pm 8$ & n.a. \\
\hline & \multicolumn{2}{|c|}{ Metabolic potency (\%) } & 100 & $82 \pm 3$ & $101 \pm 2$ & $44-45$ \\
\hline & \multicolumn{2}{|c|}{ IGF-I receptor affinity (\%) } & 100 & $156 \pm 16$ & $81 \pm 9$ & 16.2 \\
\hline & \multicolumn{2}{|c|}{ Mitogenic potency (\%) } & 100 & $66 \pm 10$ & $58 \pm 22$ & Nearly 100 \\
\hline
\end{tabular}

for the treatment of metabolic acidosis. Although the clinical effects of long-term administration of polysorbate 20 and trometamol are unknown, no $\mathrm{Zn}$ must be helpful because this allows more rapid absorption.

\section{Pharmacokinetics and biologic actions of insulin glulisine}

Pharmacokinetic studies with insulin glulisine have shown an absorption profile with a peak insulin concentration that is approximately twice that of regular human insulin, and which is reached in approximately half the time. Compared with insulin lispro, several studies ${ }^{14-16}$ have shown a faster onset of action for insulin glulisine. So far, no study has directly compared the pharmacokinetics of insulin aspart and insulin glulisine. However, Homko et al described similar pharmacokinetics and metabolic effects of insulin lispro and insulin aspart. ${ }^{17}$ Accordingly, insulin glulisine may have the most rapid onset of action of the rapid-acting insulin analogs. But, in terms of the metabolic effect, Horvath et al showed that insulin glulisine, insulin lispro, and regular insulin have similar effects on hepatic glucose production and glucose uptake. ${ }^{18}$

According to a review of the clinical pharmacokinetics and pharmacodynamics of insulin glulisine, ${ }^{12}$ dose proportionality in early, maximum and total exposure is observed for insulin glulisine over the therapeutic relevant dose range up to $0.4 \mathrm{U} / \mathrm{kg}$. The pharmacodynamic profile of insulin glulisine reflects the absorption kinetics by demonstrating a greater rate of glucose utilization, which is completed earlier and at equipotency on a molar base compared with regular human insulin. ${ }^{12}$ Dose proportionality in glucose utilization has been established for insulin glulisine in patients with type 1 diabetes in the dose range of 0.075 to $0.15 \mathrm{U} / \mathrm{kg}$, and with less intra-subject variability compared with insulin lispro and regular human insulin. ${ }^{12}$

\section{Clinical studies of insulin glulisine Glycemic control}

In general, the history of insulin glulisine is short and clinical studies are few. First, therefore, the rapid-acting insulin analogs should be described. The effects of rapid-acting insulin analogs on $\mathrm{HbA}_{1 \mathrm{c}}$ levels have been reviewed systematically and meta-analyzed. ${ }^{19}$ In that review of 49 randomized clinical studies comparing rapid-acting insulin analogs with regular human insulin, a weighted mean difference in $\mathrm{HbA}_{1 \mathrm{c}}$ of $-0.1 \%$ was determined in favor of analogs in patients with type 1 diabetes. Among patients with type 2 diabetes, there was no difference in $\mathrm{HbA}_{1 \mathrm{c}}$ between rapid-acting analogs and regular human insulin. But, only one study used insulin glulisine (37 studies used insulin lispro, 10 used insulin aspart, one used insulin lispro and insulin aspart). ${ }^{20}$ In that study, Garg et al showed that injection of insulin glulisine $0-15$ minutes before meals $(n=268)$ reduced $\mathrm{HbA}_{1 \mathrm{c}}(-0.26 \%)$ more than the injection of regular insulin 30-45 minutes before meals $(n=257)(-0.13 \%)$ in type 1 diabetes. ${ }^{20}$

Furthermore, Dailey et al reported that insulin glulisine $(n=435)$ provided a slightly greater reduction in $\mathrm{HbA}_{1 \mathrm{c}}(-0.46 \%)$ than regular insulin $(\mathrm{n}=441)(-0.30 \%)$ in 
type 2 diabetes. ${ }^{21}$ There were no between-group differences in baseline-to-end point changes in insulin dose.

On the other hand, Dreyer et al reported similar reductions in $\mathrm{HbA}_{1 \mathrm{c}}(-0.14 \%)$ with insulin glulisine and insulin lispro over a 26-week study in patients with type 1 diabetes (insulin glulisine, $\mathrm{n}=339$; insulin lispro, $\mathrm{n}=333$ ). ${ }^{22}$ In that study, there was a significant difference in changes in daily dose of insulin; $-0.86 \mathrm{U}$ in the insulin glulisine group and $+1.01 \mathrm{U}$ in the insulin lispro group.

Meanwhile, Hoogma et al described that insulin glulisine can be safely used in continuous subcutaneous insulin infusion (CSII) and does not have any adverse clinical implications compared with insulin aspart. ${ }^{23}$ These data suggest that insulin glulisine may be useful in achieving glycemic control that is greater than that with regular insulin and similar to that with the other rapid-acting insulin analogs.

\section{Hypoglycemia}

In terms of hypoglycemia, the Cochrane review of clinical studies found a lower incidence of severe hypoglycemic episodes with rapid-acting insulin analogs (median 21.8 episodes per 100 person-years in type 1 diabetes and 0.3 in type 2 diabetes) compared with regular insulin (median 46.1 episodes per 100 person-years in type 1 diabetes and 1.4 in type 2 diabetes). ${ }^{19}$ Although only one study using insulin glulisine was included in that review, the study by Garg et al showed a non-significant reduction in severe hypoglycemic episodes in the insulin glulisine groups $(8.4 \%$ with premeal insulin glulisine and $8.4 \%$ with postmeal insulin glulisine vs $10.1 \%$ with premeal regular insulin). ${ }^{20}$

Dailey et al reported that the proportion of patients with serious hypoglycemia was comparable between the insulin glulisine $(n=15,3.4 \%)$ and regular insulin $(n=11,2.5 \%)$ groups. The adjusted mean change in body weight was also similar in both treatment groups (glulisine, $1.8 \mathrm{~kg}$; regular insulin, $2.0 \mathrm{~kg}$ ). ${ }^{21}$

In Dreyer's study, the hypoglycemic episodes were comparable between insulin glulisine and insulin lispro; $3.64 \pm 4.49$ symptomatic hypoglycemic events per patient-month with insulin glulisine and $3.48 \pm 4.38$ with insulin lispro; the respective rates for severe hypoglycemia were $0.03 \pm 0.12$ and $0.02 \pm 0.11$ events per patient-month and for nocturnal hypoglycemia were $0.55 \pm 0.94$ and $0.53 \pm 0.84$ events per patient-month. ${ }^{22}$

These data suggest that, at least, insulin glulisine does not increase hypoglycemia compared with the other short-acting insulin products.

\section{Quality of life}

I searched Medline for published articles with terms related to "glulisine" and "quality-of-life". Although this search provided 8 articles, there was no original research article. Therefore, I describe the rapid-acting insulin analogs on quality-of life. In terms of quality of life and treatment satisfaction, only 12 of the 49 studies assessed in the Cochrane review included reported these data. Of these 12 studies, 7 used the Diabetes Treatment Satisfaction Questionnaire (DTSQ):19 3 studies found no significant difference in DTSQ between the treatment arms, ${ }^{24-26}$ and 4 studies showed an improvement in the analog group. ${ }^{27-30}$

\section{Immunogenicity and safety}

Because the history of insulin glulisine is still limited, I cannot describe its immunogenicity. For insulin lispro and insulin aspart, the structural changes were initially reported to result in decreased immunogenicity in in vivo studies. ${ }^{9,31}$ However, recent studies of insulin allergy demonstrated the existence of clinical allergy to these new insulin analogs and to regular insulin. ${ }^{32-34}$ Because insulin glulisine contains polysorbate 20 and trometamol as well as structural changes, one may anticipate different immunogenicity profiles compared with regular insulin.

\section{Use of insulin glulisine in clinical settings}

So far, there are few clinical studies of insulin glulisine. Firm conclusions cannot therefore be made on the utility of this new insulin analog. However, as mentioned above, insulin glulisine appears to have the most rapid onset of action of the insulin analogs and, in addition, may provide better glycemic control and reduced risk of hypoglycemia compared with regular insulin. This new insulin analog may be particularly useful in patients with high risk of hypoglycemia or insulin allergy and could also be a useful insulin to be considered for insulin pump therapy. In the future, more clinical use and good randomized long-term clinical studies with insulin glulisine will reveal the true value of this novel insulin analog.

\section{Disclosures}

The author declares no conflicts of interest.

\section{References}

1. The Diabetes Control and Complications Trial (DCCT) Research Group; The effect of intensive treatment of diabetes on the development and progression of long-term complications in insulin-dependent diabetes mellitus. N Engl J Med. 1993;329(14):977-986.

2. UK Prospective Diabetes Study (UKPDS) Group; Intensive bloodglucose control with sulphonylureas of insulin compared with conventional treatment and risk of complications in patients with type 2 diabetes (UKPDS33). Lancet. 1998;352(9131):837-853.

3. UK Prospective Diabetes Study (UKPDS) Group; Effect of intensive bloodglucose control with metformin on complications in overweight patients with type 2 diabetes (UKPDS34). Lancet. 1998;352(9131):854-865. 
4. The Action to Control Cardiovascular Risk in Diabetes Study Group; Effects of intensive glucose lowering in type 2 diabetes. $N$ Engl J Med. 2008;358(24):2545-2559.

5. The ADVANCE Collaborative Group; Intensive blood glucose control and vascular outcomes in patients with type 2 diabetes. $N$ Engl J Med. 2008;358(24):2560-2572.

6. Duckworth W, Abraira C, Moritz T, et al. Glucose control and vascular complications in veterans with type 2 diabetes. $N$ Engl J Med. 2009;360(2):129-139.

7. Maedler K, Donath MY. Beta-cells in type 2 diabetes: a loss of function and mass. Horm Res. 2004;62 Suppl 3:S67-S73.

8. Zimmet P, Alberti KGMM, Shaw J. Global and societal implications of the diabetes epidemic. Nature. 2001;414(6865):782-787.

9. Brange J, Owens DR, Kang S, Volund A. Monomeric insulins and their experimental and clinical implications. Diabetes Care. 1990;13(9): 923-954.

10. Wilde MI, McTavish D. Insulin lispro: a review of its pharmacological properties and therapeutic use in the management of diabetes mellitus. Drugs. 1997;54(4):597-614.

11. Lindholm A, Jacobsen LV. Clinical pharmacokinetics and pharmacodynamics of insulin aspart. Clin Pharmacokinet. 2001;40(9):641-659.

12. Becker RH, Frick AD. Clinical pharmacokinetics and pharmacodynamics of insulin glulisine. Clin Pharmacokinet. 2008;47(1):7-20.

13. Becker RH. Insulin glulisine complementing basal insulins: a review of structure and activity. Diabetes Technol Ther. 2007;9(1):109-121.

14. Becker RH, Frick AD, Burger F, Potgieter JH, Scholtz H. Insulin glulisine, a new rapid-acting insulin analogue, displays a rapid timeaction profile in obese non-diabetic subjects. Exp Clin Endocrinol Diabetes. 2005;113(8):435-443.

15. Heise T, Nosek L, Spitzer H, et al. Insulin glulisine: a faster onset of action compared with insulin lispro. Diabetes Obes Metab. 2007;9(5):746-753.

16. Luzio S, Peter R, Dunseath GJ, Mustafa L, Owens DR. A comparison of preprandial insulin glulisine versus insulin lispro in people with type 2 diabetes over a 12-h period. Diabetes Res Clin Pract. 2008;79(2): 269-275.

17. Homko C, Deluzio A, Jimenez C, Kolaczynski JW, Boden G. Comparison of insulin aspart and lispro. Diabetes Care. 2003;26(7): 2027-2031.

18. Horvath $\mathrm{K}$, Bock G, Regittnig W, et al. Insulin glulisine, insulin lispro and regular human insulin chow comparable end-organ metabolic effects: an exploratory study. Diabetes Obes Metab. 2008;10(6): 484-491.

19. Siebenhofer A, Plank J, Berghold A, et al. Short acting insulin analogues versus regular human insulin in patients with diabetes mellitus. Cochrane Database Syst Rev. 2006;19(2):CD003287.

20. Garg SK, Rosenstock J, Ways K. Optimized basal-bolus insulin regimens in type 1 diabetes: insulin glulisine versus regular human insulin in combination with basal insulin glargine. Endocr Pract. 2005; 11(1):11-17.
21. Dailey G, Rosenstock J, Moses RG, Ways K. Insulin glulisine provides improved glycemic control in patients with type 2 diabetes. Diabetes Care. 2004;27(10):2363-2368.

22. Dreyer M, Prager R, Robinson A, et al. Efficacy and safety of insulin glulisine in patients with type 1 diabetes. Horm Metab Res. 2005; 37(11):702-707.

23. Hoogma RPL, Schumicki D. Safety of insulin glulisine when given by continuous subcutaneous infusion using an external pump in patients with type 1 diabetes. Horm Metab Res. 2006;38(6):429-433.

24. Johansson UB, Adamson UC, Lins PE, Wredling RA. Improved blood glucose variability, $\mathrm{HbA} 1 \mathrm{c}$ insuman infusat and less insulin requirement in IDDM patients using insulin lispro in CSII. The Swedish Multicenter lispro insulin study. Diabetes Metab. 2000;26(3):192-196.

25. Gale EA. A randomized, controlled trial comparing insulin lispro with human soluble insulin in patients with type 1 diabetes on intensified insulin therapy. Diabet Med. 2000;17(3):209-214.

26. Ferguson SC, Strachan MW, Janes JM, Frier BM. Severe hypoglycaemia in patients with type 1 diabetes and impaired awareness of hypoglycaemia: a comparative study of insulin lispro and regular human insulin. Diabetes Metab Res Rev. 2001;17(4):285-291.

27. Renner R, Pfutzner A, Trautmann M, Harzer O, Sauter K, Landgraf R. Use of insulin lispro in continuous subcutaneous insulin infusion treatment. Results of a multicenter trial. Diabetes Care. 1999;22(5): 784-788.

28. Home PD, Lindholm A, Riis A. Insulin aspart vs human insulin in the management of long-term blood glucose control in type 1 diabetes mellitus: a randomized controlled trial. Diabet Med. 2000;17(11): $762-770$.

29. Bott U, Ebrahim S, Hirschberger S. Skovlund SE. Effect of the rapid-acting insulin analogue insulin aspart on quality of life and treatment satisfaction in patients with type 1 diabetes. Diabet Med. 2003;20(8):626-634.

30. Annuzzi G, Del Prato S, Arcari R, et al. Preprandial combination of lispro and NPH insulin improves overall blood glucose control in type 1 diabetic patients: a multicenter randomized crossover trial. Nutr Metab Carciovasc Dis. 2001;11(3):168-175.

31. Ottesen JL, Nilsson P, Jami J, et al. The potential immunogenicity of human insulin and insulin analogues evaluated in a transgenic mouse model. Diabetologia. 1994;37(12):1178-1185.

32. Fineberg NS, Fineberg SE, Anderson JH, Birkett MA, Gibson RG, Hufferd S. Immunologic effects of insulin lispro [(Lys(B28), Pro(B29) human insulin)] in IDDM and NIDDM patients previously treated with insulin. Diabetes. 1996;45(12):1750-1754.

33. Fineberg SE, Huang J, Brunelle R, Gulliya KS, Anderson JH Jr. Effect of long-term exposure to insulin lispro on the induction of antibody response in patients with type 1 or type 2 diabetes. Diabetes Care. 2003;26(1):89-96.

34. Lindholm A, Jensen LB, Home PD, Raskin P, Boehm BO, Rastam J. Immune responses to insulin aspart and biphasic insulin aspart in people with type 1 and type 2 diabetes. Diabetes Care. 2002;22(5):876-882.

Diabetes, Metabolic Syndrome and Obesity: Targets and Therapy

Dovepress

\section{Publish your work in this journal}

Diabetes, Metabolic Syndrome and Obesity: Targets and Therapy is an international, peer-reviewed open-access journal committed to the rapid publication of the latest laboratory and clinical findings in the fields of diabetes, metabolic syndrome and obesity research Original research, review, case reports, hypothesis formation, expert opinion and commentaries are all considered for publication. The manuscript management system is completely online and includes a very quick and fair peer-review system, which is all easy to use. Visit http://www.dovepress.com/testimonials.php to read real quotes from published authors. 